\title{
Detection of Echinococcus multilocularis and other foodborne parasites in fox, cat and dog faeces collected in kitchen gardens in a highly endemic area for alveolar echinococcosis
}

\author{
Marie-Lazarine Poulle ${ }^{1,2}$, Matthieu Bastien ${ }^{1,2,3}$, Yolan Richard ${ }^{2}$, Émilie Josse-Dupuis ${ }^{1,4}$, \\ Dominique Aubert ${ }^{1,4}$, Isabelle Villena ${ }^{1,4}$, and Jenny Knapp ${ }^{5,6}$ \\ 1 University of Reims Champagne-Ardenne, SFR Cap Santé, EA 3800 PROTAL, 51092 Reims cedex, France \\ 2 University of Reims Champagne-Ardenne, CERFE, 08240 Boult-aux-Bois, France \\ 3 French Institute for Fighting Zoonoses (ELIZ), Domaine de Pixéricourt, 54220 Malzéville, France \\ 4 University Hospital of Reims, Department of Parasitology-Mycology, 51092 Reims cedex, France \\ 5 University of Bourgogne Franche-Comté, Laboratory of Chrono-environment, UMR UFC/CNRS 6249 affi. INRA, \\ 25030 Besançon, France \\ ${ }^{6}$ University Hospital of Besançon, Department of Parasitology-Mycology, 25030 Besançon, France
}

Received 16 May 2017, Accepted 12 July 2017, Published online 26 July 2017

\begin{abstract}
Echinococcus multilocularis, Toxoplasma gondii and Toxocara spp. are foodborne parasites whose eggs or oocysts are spread in the environment via canid or felid faeces. They can cause infections in humans following the raw consumption of contaminated fruit or vegetables. In this study, their occurrence was investigated by quantitative polymerase chain reaction (qPCR) in 254 carnivore faeces deposited in 94 kitchen gardens of northeastern France that were sampled between two and six times from October 2011 to April 2013. Less than $25 \%$ of the sampled kitchen gardens contained more than $75 \%$ of the collected faeces. Of the 219 faeces that could be attributed to an emitter, cat accounted for $58 \%$, fox for $32 \%$ and dog for $10 \%$. Echinococcus multilocularis was detected in $35 \%, 11 \%$ and $7 \%$ of fox, dog and cat faeces, respectively, and Toxocara spp. in 33\%, 12\% and 5.5\% of cat, fox and dog faeces, respectively. Toxoplasma gondii was detected in $2 / 125$ cat faeces and $2 / 21$ dog faeces. The 34 faeces that tested positive for E. multilocularis were found in only 19 out of the 94 sampled kitchen gardens, and the 40 faeces that tested positive for Toxocara spp. were found in 28 of them. Consequently, some kitchen gardens appeared particularly at risk of human exposure to foodborne parasites, including E. multilocularis responsible for alveolar echinococcosis (AE), which is a serious zoonosis. In endemic areas, kitchen garden owners should be informed about the zoonotic risk linked to carnivore faeces deposits and encouraged to set up preventive measures.
\end{abstract}

Key words: Carnivore faeces, Environmental contamination, Vulpes vulpes, Felis catus, Toxocara spp., Toxoplasma gondii.

Résumé - Détection d'Echinococcus multilocularis et autres parasites transmissibles par l'alimentation dans des fèces de renards, chats et chiens récoltées dans des jardins potagers situés en aire de haute endémie d'échinococcose alvéolaire. Echinococcus multilocularis, Toxoplasma gondii et Toxocara spp. sont des parasites transmissibles par l'alimentation dont les œufs ou oocystes sont répandus dans l'environnement avec les fèces de canidés ou félidés. Ils peuvent être responsables d'infections humaines suite à la consommation crue de fruits et légumes contaminés. Leur présence a été recherchée par qPCR dans 254 fèces de carnivores déposées dans 94 potagers du nord-est de la France, échantillonnés deux à six fois entre octobre 2011 et avril 2013. Moins de $25 \%$ de ces potagers contenaient plus de $75 \%$ des fèces collectées. Parmi les 219 fèces pour lesquelles l'émetteur a pu être identifié, $58 \%$ étaient de chat, $32 \%$ de renard et $10 \%$ de chien. Echinococcus multilocularis a été détecté dans $35 \%, 11 \%$ et $7 \%$ des fèces de renard, chien et chat respectivement et Toxocara spp. dans $33 \%, 12 \%$ et $5.5 \%$ des fèces de chat, renard et chien, respectivement. Toxoplasma gondii a été détecté dans 2/125 fèces de chat et $2 / 21$ fèces de chien. Les 34 fèces testées positives pour E. multilocularis ont été trouvées dans seulement 19 des 94 potagers échantillonnés et les 40 fèces testées positives pour Toxocara spp. dans 28 d'entre eux. En conséquence, certains potagers apparaissent particulièrement à risque d'exposition humaine aux

\footnotetext{
*Corresponding author: marie-lazarine.poulle@univ-reims.fr
}

This is an Open Access article distributed under the terms of the Creative Commons Attribution License (http://creativecommons.org/licenses/by/4.0), which permits unrestricted use, distribution, and reproduction in any medium, provided the original work is properly cited. 
parasites transmissibles par l'alimentation et, notamment, à E. multilocularis responsable de l'échinococcose alvéolaire qui est une grave zoonose. En zone d'endémie, les propriétaires de potagers devraient être informés du risque zoonotique lié au dépôt de fèces de carnivores et encouragés à prendre des mesures de prévention.

\section{Introduction}

In recent years, the impact that foodborne parasites exert on food safety, food security, quality of life and livelihoods has begun to receive well-deserved global attention [46]. Humans can become infected through the ingestion of food, water or soil that has been contaminated with the infectious stage of a parasite, which is often released into the environment in animal faeces $[9,48]$. Fresh fruit and vegetables have been identified as a vehicle of transmission for half of the 24 foodborne parasites that rank at the top of the multi-criteria ranking for risk management of foodborne parasites [46]. In this ranking, Echinococcus multilocularis, Toxoplasma gondii and Toxocara spp. rank third, fourth and twentieth, making them especially worthy of concern.

Echinococcus multilocularis is a helminth parasite that is responsible for human alveolar echinococcosis (AE), a rare but severe disease that is considered one of the most serious zoonoses in the Northern Hemisphere [51]. Echinococcus multilocularis eggs are excreted in the faeces of a definitive host, which in Europe is mainly the red fox (Vulpes vulpes) [13], although free-roaming domestic dogs (Canis lupus familiaris) and domestic cats (Felis silvestris catus) can also carry this parasite $[7,12,52,53]$. Toxoplasma gondii is responsible for toxoplasmosis, a disease that is usually subclinical, but which can be fatal in immunosuppressed patients. Furthermore, transplacental transmission of $T$. gondii may lead to severe congenital infections [45]. Felids, and mostly the domestic cat, are the main definitive host of this parasite spreading its oocysts with their faeces [11]. Lastly, Toxocara spp. are responsible for toxocariasis, a zoonosis that is rarely diagnosed because it is generally asymptomatic, but that can occasionally lead to two main clinical syndromes in humans: ocular larva migrans and visceral larva migrans [39]. The species contributing most to environmental contamination by Toxocara spp. eggs in urban, suburban and rural areas are stray cat, dog and fox, respectively [36].

Echinococcus multilocularis eggs, embryonated Toxocara spp. eggs or sporulated $T$. gondii oocysts can be found in fruit and vegetables intended for human consumption; Toxocara spp. eggs have been detected in produce harvested from the soil in organic farms [24], and T. gondii and E. multilocularis DNA have been detected in fruit and vegetable samples taken from the environment [29, 30]. Echinococcus multilocularis and Toxocara spp. eggs, as well as $T$. gondii oocysts, are very resistant to adverse environmental conditions and can remain viable in the environment for years under optimal conditions of low temperatures and high humidity [2, 33, 54]. The inadvertent ingestion of eggs or oocysts from unwashed raw fruit and vegetables has been identified as a transmission risk for $\mathrm{AE}[23,40]$, toxoplasmosis $[1,34]$ and toxocariasis $[15,20]$ in humans. Faecal deposition by infected carnivore hosts in cultivated plots devoted to growing produce could thus be a crucial amplifier of the risk of zoonotic diseases. To prevent pre-harvest contamination of raw fruit and vegetables, data about such deposits are needed.

The aim of this study was to provide information on the deposit of fox, dog and cat faeces, potentially contaminated with E. multilocularis, $T$. gondii or Toxocara spp., in privately owned kitchen gardens used to grow food for household consumption. The occurrence of foodborne parasites in these faeces was investigated by using molecular analysis to screen for parasitic DNA. The study was conducted in northeastern France, which is a high-risk area for human AE [41].

\section{Materials and methods}

\section{Study area}

This study was carried out in a rural area of the Ardennes department $\left(49^{\circ} 25^{\prime} \mathrm{N}, 4^{\circ} 50^{\prime} \mathrm{E}\right)$ in northeastern France. This area was chosen because its cumulative incidence rate for human infection with AE during the 1982-2007 period was between 2.74 and 6.10, one of the highest reported in France [41]. The $1200 \mathrm{~km}^{2}$ study area was located in the southern part of the Ardennes, where data about the population dynamics of foxes and the transmission dynamics of E. multilocularis in this population were available $[18,19]$. The study area was defined to encompass 19 villages in which a contact on site (mayors and/or other contacts) was in a position to introduce us to local gardeners, given that "having confidence in the field researcher" was a prerequisite in obtaining the authorisation to sample privately owned kitchen gardens. Depending on the size of the "trust network" of each contact, between 1 and 16 kitchen gardens were sampled per village.

The study area was characterised by small villages (most with fewer than 200 inhabitants) scattered in a landscape of cultivated fields, pastureland and woodland (consisting of oak Quercus spp., beech Fagus sylvatica, hornbeam Carpinus betulus and spruce Picea abies). Red fox density was about 3-4 foxes $/ \mathrm{km}^{2}$ during the 2003-2006 period [19] and did not significantly vary from 2004 to 2015 [3]. The cat population was censused in a 460-ha area that encompassed two villages of the study area (Boult-aux-Bois and Briquenay); it reached 142 individuals $\left(\sim 30\right.$ cats $\left./ \mathrm{km}^{2}\right)$ during the 2008-2010 period [16], around ten times the abundance of the red fox population. The dog population did not exceed 30 individuals in these two villages (Poulle, pers. obs), and was therefore at least four times smaller than the cat population. The prevalence of E. multilocularis in the vulpine population in the study area was 53\% during the 2001-2005 period [19], and $36 \%$ between 2005 and 2010 in the whole Ardennes department [5]. 


\section{Sampling}

From October 2011 to January 2012, 34 privately owned kitchen gardens in six villages in the study area were surveyed once a month to search for fox, dog and cat faeces. From February to April 2013, the sampling area was enlarged, including 16 out of the previously sampled 34 kitchen gardens (from 4 out of the 6 previous villages), plus 60 others from 13 different villages, making a total of 76 kitchen gardens for this period, and 94 privately owned kitchen gardens from 19 villages over the whole study period. These 94 kitchen gardens were only used for growing food (not for ornamental plants), providing vegetables and fruit such as lettuce, potatoes, carrots, leeks, cabbages, aromatic herbs, strawberries, etc. for one household. The size of the kitchen gardens - calculated by walking their perimeter with a Global Positioning System (GPS) device - was highly variable, ranging from $7 \mathrm{~m}^{2}$ to $2862 \mathrm{~m}^{2}$ for a mean of $360.5 \pm 424.3 \mathrm{~m}^{2}$. The distance from a sampled kitchen garden to the closest dwelling or barn - also estimated by walking with a GPS device - ranged from $3 \mathrm{~m}$ to $202 \mathrm{~m}$ and averaged $24.7 \pm 2.7 \mathrm{~m}$ (Fig. 1). Of the 94 sampled kitchen gardens, 32 (34\%) were enclosed with a fence and were thus in principle not accessible to foxes, while the 62 others $(66 \%)$ had open access to foxes, dogs and cats due to the absence of continuous fencing.

Sampling was conducted from October to April, i.e. outside the gardening period to avoid damaging seedlings. In that period, kitchen gardens are deserted, which increases the probability of carnivores visiting them, and plant cover is sparse, which makes faeces detection easier. Furthermore, E. multilocularis infection pressure in foxes is probably highest during the cold months of autumn and winter in northern France, as recently shown in Zurich (Switzerland) [38], thus increasing the likelihood of contamination at this time of year. It should be noted that parasite eggs or oocysts shed in kitchen gardens between October and April stand a good chance of still being present and viable during the following gardening period (May-September) due to the optimal conditions (low temperatures and high humidity) for these parasite stages during winter in the Ardennes.

We sampled 16 kitchen gardens six times (autumn-winter 2011-2012 and winter 2013), 75 three times (17 during autumn-winter 2011-2012, 58 during winter 2013), one five times, and two just twice. Each survey consisted of a walked transect that allowed for a visual scan of the whole kitchen garden surface area. The size of the sampled area was calculated per kitchen garden by multiplying its surface area with the number of times it was sampled. It ranged from $147 \mathrm{~m}^{2}$ to $17,172 \mathrm{~m}^{2}$, averaging $1411.9 \pm 2136.8 \mathrm{~m}^{2}$ per kitchen garden, for a total sampled area size of 13.27 ha.

Fox, dog, cat or unidentified faeces were first discriminated visually in the field on the basis of shape and size, and then more accurately categorised by identifying the host species through faecal real-time PCR [26] (described below). The field researcher's accuracy in discriminating cat, dog and fox faeces was verified by comparing the identification from morphological criteria to the identification of host species from molecular analysis. Faeces were collected with disposable
(A)

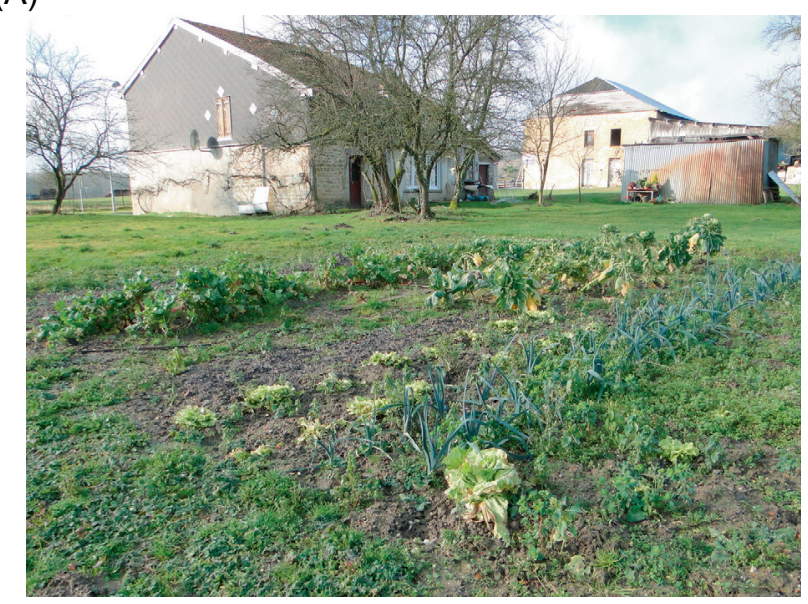

(B)

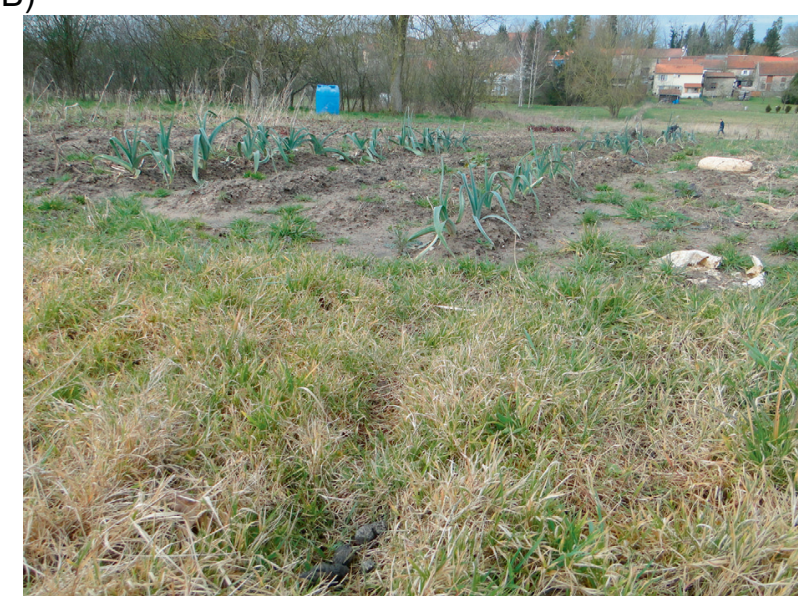

Figure 1. Two kitchen gardens in open access to carnivores and located inside (A) and outside (B) the village (at the forefront: a cat stool dropped close to the garden border).

gloves and put into separate labelled plastic bags. All collected faeces were decontaminated for 5 days at $-80{ }^{\circ} \mathrm{C}$ and then stored at $-20{ }^{\circ} \mathrm{C}$ before analysis.

\section{Molecular analyses}

\section{Copro-DNA extraction}

DNA from copro-samples was purified using the QIAamp Fast DNA Stool Mini kit (Qiagen, Hilden, Germany). We used $0.5 \mathrm{~g}$ of each copro-sample and DNA purification was carried out as described in the manufacturer's protocol.

\section{PCR inhibitor control}

The presence of PCR inhibitors was checked using a solution of $10^{5}$ spores $/ \mathrm{mL}$ of Geotrichum candidum (strain no. 6560, from the Belgian Coordinated Collections of Micro-organisms (BCCM, http://bccm.belspo.be/about/ihE. multilocularis.php) as an internal control added to the copro-sample in the first step of the extraction protocol. 
Table 1. Primers and hydrolysis probes used to detect Echinococcus multilocularis, Toxoplasma gondii and Toxocara spp. parasites, and carnivore host identification of copro-samples.

\begin{tabular}{|c|c|c|c|c|}
\hline Targeted species & Gene & Sequence name & Nucleotide sequence & Reference \\
\hline Echinococcus multilocularis & $r r n L$ & $\begin{array}{l}\text { rrn-Fwd } \\
\text { rrn-Rev } \\
\text { rrn-probe }\end{array}$ & $\begin{array}{l}\text { 5'-CTGTGATCTTGGTGTAGTAGTTGAGATTT3' } \\
\text { 5'-GGCTTACGCCGGTCTTAACTC-3' } \\
\text { 5'-TGGTCTGTTCGACCTTTTTAGCCTCCAT-3' }\end{array}$ & {$[25]$} \\
\hline Toxocara spp. & Cox 1 & $\begin{array}{l}\text { Toxo-Fwd } \\
\text { Toxo-Rev } \\
\text { Toxo-probe }\end{array}$ & $\begin{array}{l}\text { 5'-AAAATAGCCAAATCCACACTACTACCA-3' } \\
\text { 5'-GGTGTGGGACTAGTTGAACTGTGTA-3' } \\
\text { 5'-CCCCATAGTCCTCAAAG-3' }\end{array}$ & {$[26]$} \\
\hline Toxoplasma gondii & 529-rep & $\begin{array}{l}\text { Tg-Fwd } \\
\text { Tg-Rev } \\
\text { Tg-probe }\end{array}$ & $\begin{array}{l}\text { 5'-AGAGACACCGGAATGCGATCT-3' } \\
\text { 5'-CCCTCTTCTCCACTCTTCAATTCT-3' }^{\prime} \\
5^{\prime} \text {-ACGCTTTCCTCGTGGTGATGGCG-3' }\end{array}$ & [32] \\
\hline Vulpes vulpes & $C y t B$ & $\begin{array}{l}\text { Vv-Fwd } \\
\text { Vv-Rev } \\
\text { Vv-probe }\end{array}$ & $\begin{array}{l}\text { 5'-ACCTTCCCGCACCATCAAA-3' } \\
\text { 5'-TGTTGCAATCTGTAGAATAAGGCATA-3' }^{\prime} \\
\text { 5'-CTGCCTGATGGAACTTCGGGTCCC-3' }^{\prime}\end{array}$ & {$[26]$} \\
\hline Canis l. familiaris & $C y t B$ & $\begin{array}{l}\text { Cf-Fwd } \\
\text { Cc-Rev } \\
\text { Cf-probe }\end{array}$ & $\begin{array}{l}\text { 5'-CCACCCACTAGCCAAAATTGTT-3' } \\
\text { 5'-AAGTTCCATCAAGCAGAGATGTTAGA-3' } \\
\text { 5'-ATAACTCATTCATTGACCTCCCAGCGCC }\end{array}$ & {$[26]$} \\
\hline Felis s. catus & $C y t B$ & $\begin{array}{l}\text { Fc-Fwd } \\
\text { Fc-Rev } \\
\text { Fc-probe }\end{array}$ & $\begin{array}{l}\text { 5'-CCCTTCTAGGAGTCTGCCTAATCTT-3' } \\
\text { 5'-CGGTTATTGTGTCTGATGTGTAGTGT-3' }^{\prime} \text { 5'-AAATCCTCACCGGCCTCTTTTTGGC-3' }\end{array}$ & {$[26]$} \\
\hline Geotrichum candidum & $C y t B$ & $\begin{array}{l}\text { Geo-Fwd } \\
\text { Geo-Rev } \\
\text { Geo-probe }\end{array}$ & $\begin{array}{l}\text { 5'-CACCGCCCGTCGCTAC-3' } \\
\text { 5'-AGAAAAGTTGCCCTCTCCAGTT-3' } \\
5^{\prime} \text {-TCAATCCGGAAGCCTCACTAAGCCATT-3' }\end{array}$ & {$[25]$} \\
\hline
\end{tabular}

Then, a qPCR was performed with an expected cycle threshold (Cq) value under 34 cycles, as previously described by Knapp et al. [25]. When inhibitors were detected, qPCR was performed a second time on copro-DNA diluted 1:10 and $1: 100$, respectively.

\section{E. multilocularis and Toxocara spp. qPCR diagnosis}

In order to detect the presence of E. multilocularis and Toxocara spp. parasites in the copro-samples, quantitative polymerase chain reactions (qPCRs) were performed on copro-DNA extracts, as previously described by Knapp et al. [25] for E. multilocularis, and Knapp et al. [26] for Toxocara spp. Briefly, a duplex qPCR was performed using TaqMan technology, with hydrolysis probes and TaqMan Gene Expression Master Mix 2X (Life Technologies, Foster City, CA, USA) to simultaneously detect the parasite and the PCR inhibitors (rrn-E. multilocularis primers and probe were associated with Geo primers and probe, and Tox primers and probe were associated with Geo primers and probe, Table 1). The qPCRs were performed with 45 cycles for the two parasites as previously described, in a 7500 Fast Real-Time PCR System (Applied Biosystems, Foster City, CA, USA). Results were analysed using 75002.0 .5 software. A qPCR with $\mathrm{Cq} \leq 45$ cycles allowed us to determine the presence of parasites but qPCR results did not enable estimation of the amount of eggs or oocysts per faecal sample, and it was therefore not possible to estimate the amount of absolute contribution of fox, $\operatorname{dog}$ and cat to the contamination of gardens. Molecular analyses were performed at the Chronoenvironment Laboratory, UMR 6249, UBFC, Besançon, France.

\section{Toxoplasma gondii diagnosis}

DNA extracts were subjected to a PCR targeting a specific repeated element of $529 \mathrm{bp}$ [44] and performed using an iQ5 instrument (Bio-Rad, Hercules, CA, USA) as follows. A Toxoplasma gondii-specific target region (GenBank Accession No. AF487550) was amplified with a labelled TaqMan probe (5'6FAM-ACGCTTTCCTCGTGGTGATGGCG-3'TAMRA) and DNA oligonucleotide primers (5'-AGAGACACCGGAATGCGATCT- ${ }^{\prime}$ and 5'-CCCTCTTCTCCACTCTTCAATTCT-3') [32]. The amplification mixture was composed of $12.5 \mu \mathrm{L}$ of $2 \times$ reaction mixture (Platinum Quantitative PCR SuperMix-UDG, Invitrogen, Carlsbad, CA, USA), $3.5 \mathrm{mM} \mathrm{MgCl}_{2}, 0.5 \mu \mathrm{M}$ of each oligonucleotide primer, $0.2 \mu \mathrm{M}$ TaqMan probe, $1 \mu \mathrm{L}$ of $1 \%$ bovine serum albumin to increase the PCR performance, and $5 \mu \mathrm{L}$ of template DNA, for a final volume of $25 \mu \mathrm{L}$. The reaction mixture was initially incubated for $3 \mathrm{~min}$ at $50{ }^{\circ} \mathrm{C}$ to allow for uracil-N-glycosylase (UNG) activity. This first incubation was followed by a second incubation of $3 \mathrm{~min} 30 \mathrm{~s}$ at $95^{\circ} \mathrm{C}$ to denature the DNA template, inactivate the UNG enzyme and activate the Platinum Taq DNA Polymerase. Samples were amplified as follows: 45 cycles of denaturation at $95{ }^{\circ} \mathrm{C}$ for 
Table 2. Concordance matrix between faeces identification based on morphological assessment and faeces identification based on molecular analysis (by qPCR). In grey cells: occurrence of faeces per species for which the morphological identification was concordant with the molecular analysis (e.g. 19 out of 23 faeces identified as fox faeces from morphological examination were confirmed in molecular analysis). In other cells: the number and percentage of faeces for which the morphological identification did not correspond with the molecular analysis. Percentages are given with their $95 \%$ confidence intervals.

\begin{tabular}{lcccccc}
\hline & & Fox by qPCR & Dog by qPCR & Cat by qPCR \\
\hline Fox & $19 / 23$ & $82.6 \%(61.2-95.0)$ & $0 / 23$ & 0 & $4 / 23$ & $17.4 \%(4.9-38.8)$ \\
Dog & $3 / 19$ & $15.8 \%(3.4-39.6)$ & $12 / 19$ & $63.2 \%(38.3-83.7)$ & $4 / 19$ & $21.1 \%(6.0-45.5)$ \\
Cat & $6 / 62$ & $9.7 \%(3.6-19.9)$ & $2 / 62$ & $3.2 \%(0.4-11.1)$ & $54 / 62$ & $87.1 \%(76.1-94.3)$ \\
\hline
\end{tabular}

$15 \mathrm{~s}$, and annealing/extension at $60{ }^{\circ} \mathrm{C}$ for $1 \mathrm{~min}$. Each sample was tested in duplicate. Negative controls were included from DNA extraction to PCR amplification steps, and each PCR run contained both negative and positive controls. No amplification results were systematically obtained for the negative control. A PCR with $\mathrm{Cq} \leq 45$ cycles allowed us to determine the presence of parasites. Molecular analyses were performed at the Laboratory of Parasitology and Mycology, EA3800 PROTAL, Reims University, France.

\section{Host faecal test}

The field researchers' morphological identification of carnivore faeces was confirmed by a molecular host faecal test developed by Knapp et al. [26], using TaqMan probes and based on qPCR technology. Briefly, duplex qPCRs were performed to identify a stool as that of a red fox, dog or cat (Table 1) in the expected ranges of $\mathrm{Cq}$ values, as previously described.

\section{Statistical analysis}

Correlations between the number of faeces found and the sample sizes, and between the number of faeces testing positive for parasites and the total number of faeces found, were tested by the Spearman correlation test. The frequencies of faeces with positive qPCR results were given with their $95 \%$ confidence intervals and were compared using chi-square tests. A Fisher's exact test was carried out when sample size was not sufficient. All statistical analyses were performed with $\mathrm{R}$ version 3.1.3.

\section{Results}

A total of 85 faeces were collected from October 2011 to January 2012, and 169 faeces from February to March 2013, resulting in 254 faeces collected over the 2011-2013 period. Of the 254 faeces analysed, 194 (76.4\%) were visually identified in the field from morphological criteria (size and shape), $191(75.2 \%)$ provided usable DNA and $143(56.3 \%)$ allowed for identification of the emitter species using qPCR analysis. Of the 104 faeces with a specific identification based both on morphological criteria and qPCR analysis, 19 out of 23 faeces $(82.6 \%)$ and 54 out of 62 faeces $(87.1 \%)$, respectively, attributed to fox and cat in the field were confirmed by qPCR analysis (Table 2). Thus, morphological criteria alone were considered reliable for the identification of cat and fox faeces. Consequently, the 50 faeces attributed to cat in the field but that did not permit qPCR identification of the emitter were considered as cat faeces, and the 26 faeces attributed to fox based on their morphological identification without molecular confirmation were considered as fox faeces. In contrast, as only 12 out of $19(63.2 \%)$ faeces attributed to dog in the field were confirmed as dog stools by qPCR analysis (Table 2), morphological identification alone was not considered reliable enough to attribute faeces to dog. For that reason, only the 22 faeces identified as dog faeces by molecular analysis (among them some that were unidentified or misidentified in the field) were considered for further analysis. Of the 60 unidentified faeces in the field, 39 were identified by qPCR. In the 62 stools in which the Geotricum qPCR was inhibited, 40 could be identified by morphological and/or molecular analysis. Of these, 37 were attributed to cat, one to dog and two to fox. Cat faeces therefore accounted for almost all the identified faeces that had inhibitors.

To sum up, 219 out of $254(86.2 \%)$ of the collected faeces could be attributed to a species based on qPCR analysis and/or visual identification. Of these, $127(58 \%)$ were cat faeces, $70(32 \%)$ were fox faeces and $22(10 \%)$ were dog faeces.

No stools were found in 39 of the 94 sampled gardens (41.5\%), whereas 1-21 stools were collected in the 55 others (Fig. 2A). The kitchen garden where the highest number of faeces were collected (21 faeces: 16 fox stools, 3 cat stools, $1 \mathrm{dog}$ stool and 1 undetermined stool) was the farthest from buildings or barns (by a distance of $234 \mathrm{~m}$ ). The 23 out of 94 kitchen gardens $(24.5 \%)$ where at least four stools were found were the source of 191 out of 254 (75.2\%) faeces. As might be expected, the number of faeces found per kitchen garden was significantly correlated with the surface sampled $(r=0.54, p<0.0001)$. Of the 52 kitchen gardens where at least one identified carnivore stool was found, 35 (67\%) had only cat, fox or dog faeces, $10(19 \%)$ had both cat and fox faeces, $1(2 \%)$ had both $\operatorname{dog}$ and fox faeces, and $6(12 \%)$ had cat, dog and fox faeces (Fig. 2A). Of the 23 kitchen gardens that had only cat faeces, $8(33 \%)$ were enclosed. There were four kitchen gardens with more than 10 cat faeces: these were characterised by the close proximity of a site where cats were fed (by the kitchen garden owners or their neighbours).

Of the 74 faeces that yielded positive qPCR or PCR results for the detection of parasite DNA, three tested positive for both Toxocara spp. and E. multilocularis (two fox stools and one cat stool) and two others tested positive for both Toxocara spp. and T. gondii (one cat stool and one dog stool), resulting in a total 


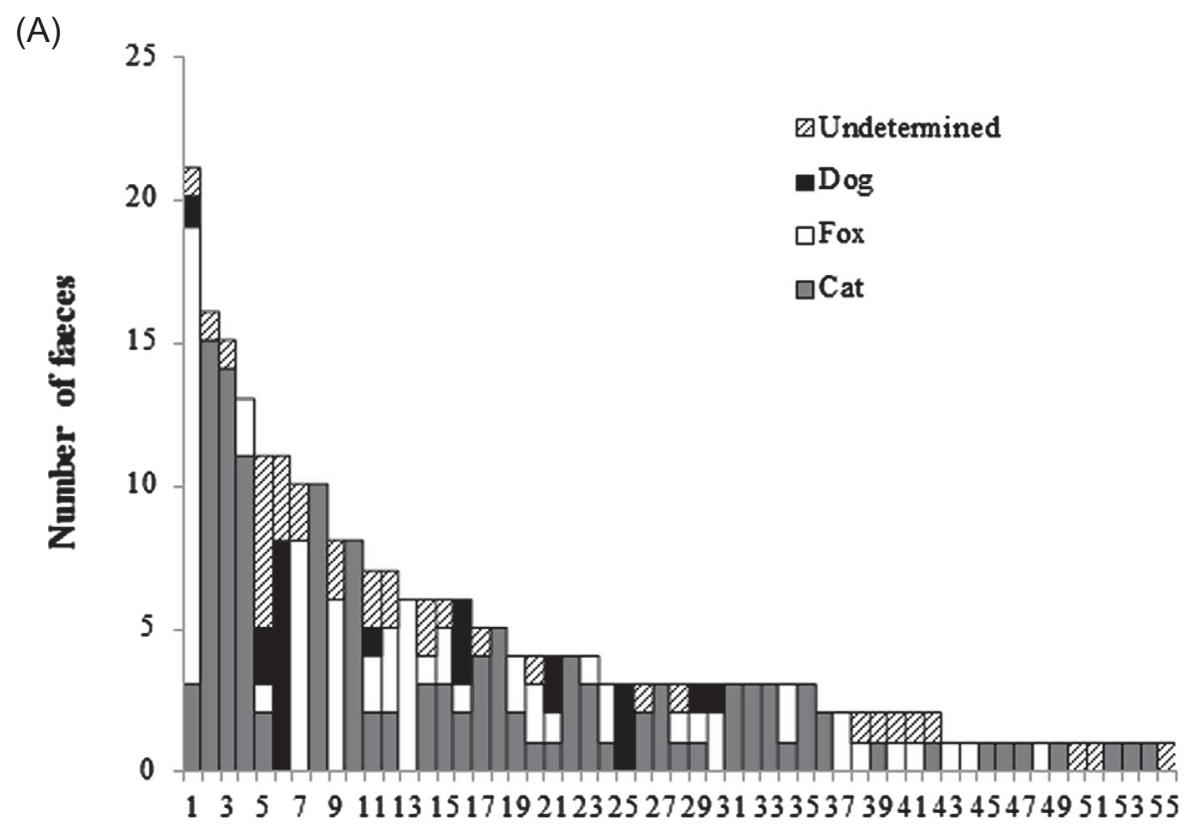

(B)

Kitchen garden identification number

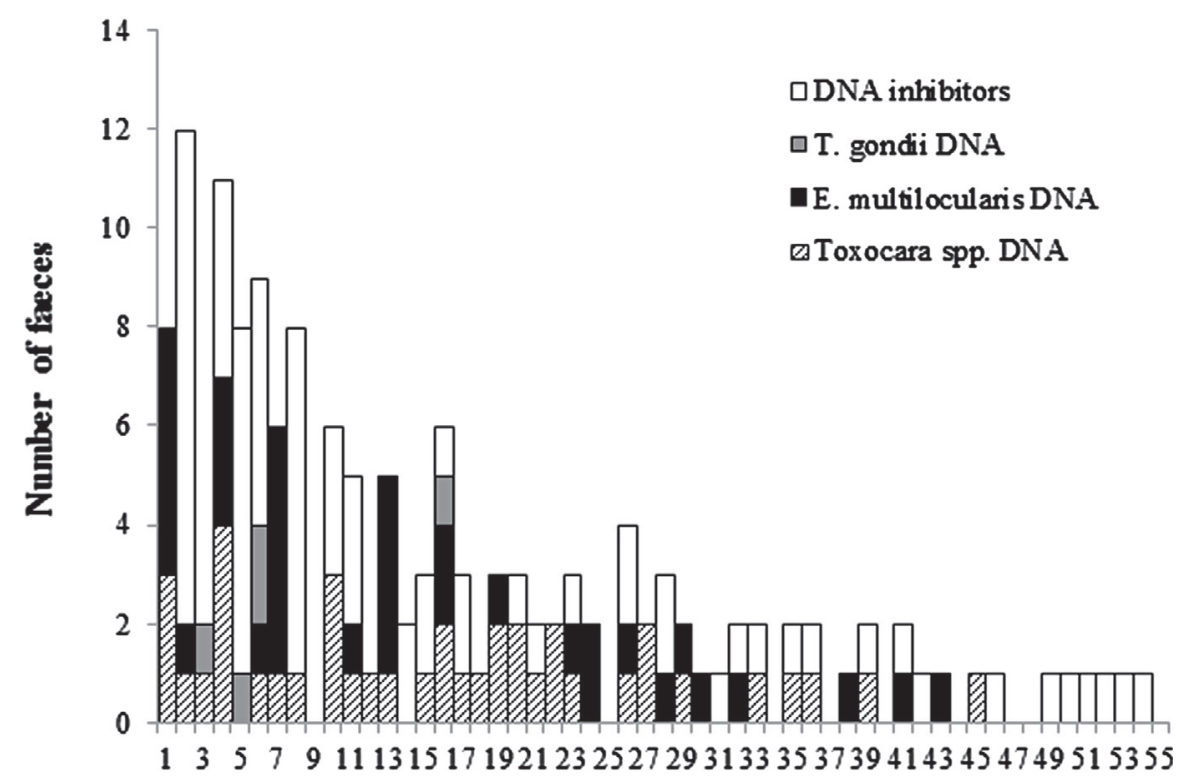

Kitchen garden identification number

Figure 2. The number of carnivore faeces collected in the 55 (out of 94) sampled kitchen gardens in which at least one stool was collected; (A) the number of cat, fox, dog and unidentified faeces; (B) the number of faeces that yielded positive results for the detection of Toxocara spp., Echinococcus multilocularis or Toxoplasma gondii, as well as the number of faeces with DNA inhibitors.

of 79 parasite DNA detections (Table 3). The occurrence of Toxocara spp. and E. multilocularis DNA did not significantly differ within the total sampling, with $20.7 \%$ and $18.3 \%$ of stools testing positive, respectively (Table $3, \chi^{2}$ test $=0.22$, $p=0.64)$. However, the occurrence of Toxocara spp. and E. multilocularis differed significantly $(p<0.001)$ between cat, fox and dog faeces that yielded qPCR results (Table 3 ). Toxocara spp. was the most frequently detected parasite in cat faeces (33.3\%), while its occurrence was significantly lower in fox faeces $(11.6 \%)$ and $\operatorname{dog}$ faeces $(5.5 \%)(p<0.001)$. In contrast, $E$. multilocularis was significantly more frequent in fox faeces $(34.8 \%)$ than in cat faeces $(7 \%)$ or dog faeces $(11.1 \%)(p<0.0001)$. Toxoplasma gondii was detected in 2 out of 125 cat faeces and 2 out of 21 dog faeces and was not detected in fox faeces (Table 3). The two dog faeces that tested positive for $T$. gondii PCR were collected within a one-month interval in the same enclosed kitchen garden. They originated from the same privately owned dog. Of the total 
Table 3. Occurrence of cat, fox, dog and unidentified faeces collected in kitchen gardens that yielded positive PCR results for the detection of Echinococcus multilocularis, Toxocara spp. or Toxoplasma gondii DNA as compared to the total number of faeces that yielded PCR results for the given emitter and parasite (i.e. faeces without inhibitors). Percentages are given with their $95 \%$ confidence intervals.

\begin{tabular}{|c|c|c|c|c|c|c|}
\hline & \multicolumn{2}{|c|}{ E. multilocularis } & \multicolumn{2}{|c|}{ Toxocara spp. } & \multicolumn{2}{|c|}{ Toxoplasma gondii } \\
\hline Cat & $6 / 86$ & $7 \%(2.6-14.6)$ & $31 / 93$ & $33.3 \%(27.0-48.6)$ & $2 / 125$ & $1.6 \%(0.1-5.7)$ \\
\hline Red fox & $24 / 69$ & $34.8 \%(23.5-47.6)$ & $8 / 69$ & $11.6 \%(5.1-21.6)$ & $0 / 28$ & $0 \%$ \\
\hline Dog & $2 / 18$ & $11.1 \%(1.4-34.7)$ & $1 / 18$ & $5.5 \%(0.1-27.3)$ & $2 / 21$ & $9.5 \%(1.2-30.4)$ \\
\hline Unidentified & $2 / 13$ & $15.4 \%(1.9-45.4)$ & $0 / 13$ & $0 \%$ & $1 / 25$ & $4.0 \%(0.1-20.3)$ \\
\hline Total & $34 / 186$ & $18.3 \%(13.0-24.6)$ & $40 / 193$ & $20.7 \%(15.2-27.1)$ & $5 / 199$ & $2.5 \%(0.8-5.7)$ \\
\hline
\end{tabular}

eight faeces collected from this dog, one was contaminated with both $T$. gondii and Toxocara spp, one was contaminated with $T$. gondii and one was contaminated with E. multilocularis.

In 7 of the 55 kitchen gardens where at least one stool was found, all the stools had inhibitors, resulting in an absence of qPCR results (Fig. 2B). The 79 detections of parasite DNA originated from 36 of the 94 sampled kitchen gardens $(38.3 \%)$. The number of parasite detections was correlated to the number of faeces collected per kitchen garden $(r=0.55, p<0.0001)$. The 34 faeces that tested positive for E. multilocularis were collected in 19 of the 94 sampled kitchen gardens $(20.2 \%)$, while 28 of the 94 sampled kitchen gardens $(29.8 \%)$ contained the 40 faeces that tested positive for Toxocara spp. (Fig. 2B).

\section{Discussion}

To our knowledge, this study is the first to provide information about the occurrence of E. multilocularis, Toxocara spp. and T. gondii in cat, $\operatorname{dog}$ and fox faeces deposited in privately owned kitchen gardens located in a highly endemic area for AE. As an exploratory study, it is based on an opportunistic sampling design leading to uneven sampling regarding villages, sampling periods and sample size per garden. However, despite this and other methodological issues, this study gives an initial insight into the key role kitchen gardens may play in the transmission of foodborne parasites from carnivores to humans.

The use of molecular screening (PCR and qPCR) allowed the identification of the emitter species of faecal samples as well as the detection of the parasite DNA contained in the sample. The proportion of samples usable for molecular analysis $(75.2 \%)$ was lower than previously described in Knapp et al. [25], where less than $2 \%$ of the samples contained PCR inhibitors. However, in Knapp et al. [25], only fox stools were investigated, while in this study we also investigated dog and cat faeces, with cat stools accounting for a very large percentage of the faecal samples with inhibitors. As a high level of calcium is known to alter DNA quality [37], one might assume that cat and dog copro-samples had a higher level of calcium than fox copro-samples due to the high proportion of pet food in these animals' diet. The correct morphological identification of carnivore stools was high for cat stools $(87 \%$ of faeces were correctly identified in the field) and fox stools (83\% were correctly identified), but was lower for dog stools (63\% were correctly identified). These results indicate that identifying copro-material remains difficult, even for specialists, and that confirmation by a second technique is often advisable.

In the majority of previous studies dealing with the detection of foodborne parasites in copro-samples from cat, fox or dog populations, only one faecal sample was collected per individual. In this study, faeces were collected in the field, which means that we could not establish whether multiple samples from the same individual were collected. For this reason, our results have a disadvantage in that they cannot be compared to those from studies on the prevalence of E. multilocularis in fox and dog populations (e.g. $[12,52])$ or the prevalence of Toxocara spp. in fox, dog and cat populations (e.g. [4, 55]). However, they do serve to provide a general view of the contamination risk in kitchen gardens. Indeed, as discussed by Lass et al. [31], the detection of parasite DNA in faeces is evidence of their presence in the environment and indicates a potential risk for humans, even though this alone does not allow the level of risk to be determined - this would require investigating the viability of the infective stage of the parasites and the parasite burden per faeces. In line with Conraths and Deplazes [6], we consider that data from faeces collected in the environment has the advantage of yielding more relevant information for preventing foodborne parasite transmission than investigating prevalence in definitive host populations, since humans run a much higher risk of contamination from contact with the environment than from contact with definitive hosts. Furthermore, such data also have the advantage of allowing hotspots of intensive transmission to be identified, some having already been identified in the transmission of E. multilocularis to its intermediate hosts [43] and in the transmission of Toxocara spp. to humans [35].

Almost one-third of the faeces we collected in kitchen gardens were from fox. This relatively high occurrence of faeces from a wild carnivore in close proximity to humans is not surprising since foxes are known to come close to villages and buildings at night in rural areas [21, 28]. This is likely to explain why E. multilocularis DNA was detected close to rural homes in Poland, where foxes approach human settlements in search of food [50]. In our study, $66 \%$ of the sampled kitchen gardens were in open access, i.e. easily accessible to canids, and most were near pastures, meadows or forest edges where voles, the main fox prey in the area, are generally abundant [18]. Accessibility and food availability could thus explain the relatively frequent collection of fox faeces in the sampled kitchen gardens. The detection of E. multilocularis DNA in almost $35 \%$ of the kitchen gardens is thus not surprising since more than $50 \%$ of foxes necropsied during the 2001-2005 
period were found to carry E. multilocularis worms in their intestines [19] and there is no reason to assume that the prevalence of this parasite in the vulpine population was lower during the sampling period of our study. Echinococcus multilocularis was also detected in two dog faeces (out of 18) collected in kitchen gardens from two different villages. Given the high reproductive potential of this parasite in fox and dog [22], we can assume that the E. multilocularis DNA detected in fox and dog faeces originated from eggs. Nonetheless, the distinction between viable and non-viable eggs would provide valuable information when considering the infection risk. In any case, given the occurrence of fox faeces in kitchen gardens, the occurrence of E. multilocularis DNA in these faeces as well as in dog faeces, and the non-homogeneous distribution of faeces testing positive for parasites we observed, the results indicate that fruits and vegetables cultivated in some kitchen gardens could be at risk of exposing consumers to E. multilocularis. The detection of E. multilocularis DNA in different environmental matrices in a kitchen garden belonging to an AE patient in Poland [30] tends to confirm this hypothesis. Similarly, the contamination of market gardens by feral dog faeces was identified as being probably responsible for numerous cases of human cystic echinococcosis in Jordan [10].

Cat faeces in kitchen gardens were characterised by their abundance, accounting for $58 \%$ of the 219 faeces identified from morphological and/or molecular identification. This high occurrence probably resulted both from the relatively high density of the cat population, as compared to the dog and fox populations, and to the selection of kitchen gardens by cats to defecate because they seek to cover their faeces with loose soil. Due to this covering behaviour, the detection of cat faeces in kitchen gardens may have been less exhaustive than the detection of fox and dog faeces. However, the possible underestimation of cat faeces was probably low in the November to February sessions because the soil was generally frozen or wet, deterring cats from burying their faeces. It may have been higher in March and April, when the soil had thawed and some cat faeces may have been deeply buried as gardeners often turn over the soil during this period. Although E. multilocularis DNA was detected in almost $7 \%$ of the cat faeces collected in kitchen gardens, cats probably play a minor role in the transmission of this parasite since the reproductive potential of E. multilocularis is thought to be low in this species [22]. This assumption is supported by the fact that no eggs were found in the 10 out of 321 cat faeces collected in two villages of the study area that tested positive for E. multilocularis in a molecular analysis, as well as by the fact that the infected cats originating from these villages carried only immature worms [53]. However, Knapp et al. [27] reported eggs in cat faeces in eastern France, observing entire eggs, with shell and hooks, under the microscope. The role of cat in E. multilocularis transmission in terms of the infectivity of eggs warrants further study.

The 33.3\% (27.0-48.6) occurrence of Toxocara spp. DNA identified by qPCR in cat faeces collected in kitchen gardens is very similar to the $35.7 \%(31.2-40.1)$ occurrence of eggs from this parasite detected by the flotation technique on faeces collected in the environment from a stray cat population in Argentina [49]. This similarity may be explained by the fact that in our study, as in that of Sommerfelt et al. [49], only a small percentage of the individuals from the outdoor cat population depositing the faeces collected in kitchen gardens had been dewormed [16]. In contrast, the 11.6\% (5.1-21.6) occurrence of Toxocara spp. DNA in fox faeces collected in kitchen gardens was lower than the $22.3 \%$ (19.9-24.7) occurrence of eggs from this parasite in 1213 fox faeces collected in the field in Belarus and examined with standard flotation techniques [47]. The direct observation of eggs would allow for more reliable assessment of the zoonotic risk related to the detection of Toxocara spp. DNA in cat, fox and dog faeces collected in kitchen gardens. Nonetheless, the occurrence of faeces testing positive in our sample suggests that this risk may be significant.

Toxoplasma gondii DNA was detected in $1.6 \%$ of the cat faeces collected in kitchen gardens; this is in line with the low proportion of individuals found to excrete oocysts in cat populations [11]. Toxoplasma gondii was also detected in two dog faeces, which was an unexpected result as canids do not usually excrete $T$. gondii oocysts. Toxoplasma gondii DNA detected by qPCR may originate from bradyzoites of infected prey a cat or dog has just ingested, as has been demonstrated experimentally by Poulle et al. [42]. Furthermore, as coprophagy is relatively common in $\operatorname{dog}[17,36]$, the $T$. gondii DNA detected in the two dog faeces may also have resulted from the ingestion of cat faeces with $T$. gondii oocysts, as has been suggested to explain the detection of Toxocara cati and other atypical parasites in dog faeces $[14,36]$. More of a concern could be the detection of E. multilocularis and Toxocara spp. in dog faeces collected in kitchen gardens; particularly the discovery of two faeces yielding positive qPCR results for these parasites in the same kitchen garden. The fact that the dog that deposited these faeces was confined in this kitchen garden indicates that eggs from this infected individual were shed where fruit and vegetables were grown and could thus present a zoonotic risk for the dog's owners and any consumers of the garden's produce.

In conclusion, this study revealed that faecal deposition by cats, foxes and dogs does not appear minor in certain kitchen gardens of northeastern France, nor does the occurrence of foodborne zoonotic parasites in their faeces. In particular, the high occurrence of E. multilocularis DNA in fox and dog faeces emphasises the need to prevent access to kitchen gardens by canids to the extent possible in areas where $\mathrm{AE}$ is endemic. This could be done through information campaigns to make gardeners aware of the zoonotic threat, by promoting the enclosure of kitchen gardens with fences, by reducing food availability in proximity and by avoiding using kitchen gardens as dog pens. In addition, the deposition of faeces in kitchen gardens by free-roaming cats can lead to a risk of human exposure to Toxocara spp. that should not be underestimated [8]. Preventing free-roaming cats from accessing kitchen gardens is difficult as they can easily climb fences, but other recommendations to limit the risk of toxocariasis and toxoplasmosis infections could be promoted, such as washing hands after contact with soil or plants, and cooking or thoroughly washing fruit and vegetables in contact with soil. These recommendations would also be valuable in helping to prevent $\mathrm{AE}$ infection. 
Acknowledgements. This work was partly supported by a grant from the Conseil Général des Ardennes. We are very grateful to the 94 Ardennes inhabitants who allowed us to survey their kitchen gardens and to our 19 village contacts who helped us in obtaining these authorisations. We would also like to thank Jordan Carvalho for his contribution to the collection and analysis of faeces, Elise Bradbury for her editorial review, as well as Prof. Emmanuelle Gilot-Fromont and the two anonymous reviewers for their helpful comments on the first draft of the manuscript.

\section{References}

1. Alvarado-Esquivel C, Estrada-Martínez S, Liesenfeld O. 2011. Toxoplasma gondii infection in workers occupationally exposed to unwashed raw fruits and vegetables: a case control seroprevalence study. Parasite \& Vectors, 4, 235.

2. Azam D, Ukpai OM, Said A, Abd-Allah GA, Morgan ER. 2012. Temperature and the development and survival of infective Toxocara canis larvae. Parasitology Research, 110, 649-656.

3. Bastien M. 2017. Contamination des terrains potagers par Echinococcus multilocularis, Toxoplasma gondii et Toxocara spp, parasites responsables de zoonoses transmises par l'alimentation. PhD thesis, Reims Champagne Ardenne University, Reims, France.

4. Brochier B, De Blander H, Hanosset R, Berkvens D, Losson B, Saegerman C. 2007. Echinococcus multilocularis and Toxocara canis in urban red foxes (Vulpes vulpes) in Brussels, Belgium. Preventive Veterinary Medicine, 80, 65-73.

5. Combes B, Comte S, Raton V, Raoul F, Boué F, Umhang G, Favier S, Dunoyer C, Woronoff N, Giraudoux P. 2012. Westward spread of Echinococcus multilocularis in foxes, France, 2005-2010. Emerging Infectious Diseases, 18, 2059-2062.

6. Conraths FJ, Deplazes P. 2015. Echinococcus multilocularis: epidemiology, surveillance and state-of-the-art diagnostics from a veterinary public health perspective. Veterinary Parasitology, 213, 149-161.

7. Deplazes P, van Knapen F, Schweiger A, Overgaauw PAM. 2011. Role of pet dogs and cats in the transmission of helminthic zoonoses in Europe, with a focus on echinococcosis and toxocarosis. Veterinary Parasitology, 182, 41-53.

8. Deutz A, Fuchs K, Auer H, Kerbl U, Aspöck H, Köfer J. 2005. Toxocara-infestations in Austria: a study on the risk of infection of farmers, slaughterhouse staff, hunters and veterinarians. Parasitolology Research, 97, 390-394.

9. Dorny P, Praet N, Deckers N, Gabriel S. 2009. Emerging food-borne parasites. Veterinary Parasitology, 163, 196-206.

10. Dowling PM, Abo-Shehada MN, Torgerson PR. 2000. Risk factors associated with human cystic echinococcosis in Jordan: results of a case-control study. Annals of Tropical Medicine \& Parasitology, 4, 69-75.

11. Dubey JP. 2010. Toxoplasmosis of Animals and Man, 2nd edn. Boca Raton: CRC Press.

12. Dyachenko V, Pantchev N, Gawlowska S, Vrhovec MG, Bauer C. 2008. Echinococcus multilocularis infections in domestic dogs and cats from Germany and other European countries. Veterinary Parasitology, 157, 244-253.

13. Eckert J, Deplazes P, Kern P. 2011. Alveolar echinococcosis (Echinococcus multilocularis) and other neotropical forms of Echinococcus (Echinococcus vogeli and Echinococcus oligarthrus), in Oxford Textbook of Zoonoses: Biology, Clinical
Practice, and Public Health Control, Palmer SR, Editor. Oxford University Press: Oxford. p. 669-699.

14. Fahrion AS, Schnyder M, Wichert B, Deplazes P. 2011. Toxocara eggs shed by dogs and cats and their molecular and morphometric species-specific identification: is the finding of T. cati eggs shed by dogs of epidemiological relevance? Veterinary Parasitology, 177, 186-189.

15. Fallah AA, Makhtumi Y, Pirali-Kheirabadi K. 2016. Seasonal study of parasitic contamination in fresh salad vegetables marketed in Shahrekord, Iran. Food Control, 60, 538-542.

16. Forin-Wiart M-A, Gotteland C, Gilot-Fromont E, Poulle M-L. 2014. Assessing the homogeneity of individual scat detection probability using the bait-marking method on a monitored freeranging carnivore population. European Journal of Wildlife Research, 60, 665-672.

17. Frenkel JK, Parker BB. 1996. An apparent role of dogs in the transmission of Toxoplasma gondii: the probable importance of xenosmophilia. Annals of the New York Academy of Sciences, 791, 402-407.

18. Guislain M-H, Raoul F, Poulle M-L, Giraudoux P. 2007. Fox faeces and vole distribution on a local range: ecological data in a parasitological perspective for Echinococcus multilocularis. Parasite, 14, 299-308.

19. Guislain M-H, Raoul F, Giraudoux P, Terrier M-E, Froment G, Hubert F, Poulle M-L. 2008. Ecological and biological factors involved in the transmission of Echinococcus multilocularis in the French Ardennes. Journal of Helminthology, 82, 143-151.

20. Gyang PV, Akinwale OP, Lee Y-L, Chuang T-W, Orok AB, Ajibaye O, Liao C-W, Chen P-C, Chou C-M, Huang Y-C, Barghouth U, Fan C-K. 2015. Seroprevalence, disease awareness, and risk factors for Toxocara canis infection among primary schoolchildren in Makoko, an urban slum community in Nigeria. Acta Tropica, 146, 135-140.

21. Janko C, Schröder W, Linke S, König A. 2012. Space use and resting site selection of red foxes (Vulpes vulpes) living near villages and small towns in Southern Germany. Acta Theriologica, 57, 245-250.

22. Kapel CMO, Torgerson PR, Thompson RCA, Deplazes P. 2006. Reproductive potential of Echinococcus multilocularis in experimentally infected foxes, dogs, raccoon dogs and cats. International Journal for Parasitolology, 36, 79-86.

23. Kern P, Ammon A, Kron M, Sinn G, Sander S, Petersen LR, Gaus W, Kern P. 2004. Risk factors for alveolar echinococcosis in humans. Emerging Infectious Diseases, 10(12), 2088-2093.

24. Kłapeć T, Borecka A. 2012. Contamination of vegetables, fruit and soil with geohelmints eggs on organic farms in Poland. Annals of Agricultural and Environmental Medicine, 19, 421-425.

25. Knapp J, Millon L, Mouzon L, Umhang G, Raoul F, Ali ZS, Combes B, Comte S, Gbaguidi-Haore H, Grenouillet F, Giraudoux P. 2014. Real time PCR to detect the environmental faecal contamination by Echinococcus multilocularis from red fox stools. Veterinary Parasitology, 201, 40-47.

26. Knapp J, Umhang G, Poulle M-L, Millon L. 2016. Development of a real-time PCR for a sensitive one-step coprodiagnosis allowing both the identification of carnivore feces and the detection of Toxocara spp. and Echinococcus multilocularis. Applied and Environmental Microbiology, 82(10), 2950-2958. 
27. Knapp J, Combes B, Umhang G, Aknouche S, Millon L. 2016. Could the domestic cat play a significant role in the transmission of Echinococcus multilocularis? A study based on qPCR analysis of cat feces in a rural area in France. Parasite, 23, 42.

28. Krauze-Gryz D, Gryz JB, Goszczyński J, Chylarecki P, Żmihorski M. 2012. The good, the bad, and the ugly: space use and intraguild interactions among three opportunistic predators - cat (Felis catus), dog (Canis lupus familiaris), and red fox (Vulpes vulpes) - under human pressure. Canadian Journal of Zoology, 90, 1402-1413.

29. Lass A, Pietkiewicz H, Szostakowska B, Myjak P. 2012. The first detection of Toxoplasma gondii DNA in environmental fruits and vegetables samples. European Journal of Clinical Microbiology \& Infectious Diseases, 31, 1101-1108.

30. Lass A, Szostakowska B, Myjak P, Korzeniewski K. 2015. The first detection of Echinococcus multilocularis DNA in environmental fruit, vegetable, and mushroom samples using nested PCR. Parasitology Research, 114, 4023-4029.

31. Lass A, Szostakowska B, Myjak P, Korzeniewski K. 2016. Fresh fruits, vegetables and mushrooms as transmission vehicles for Echinococcus multilocularis in highly endemic areas of Poland: reply to concerns. Parasitology Research, 115, 3637-3642.

32. Lélu M, Gilot-Fromont E, Aubert D, Richaume A, Afonso E, Dupuis E, Gotteland C, Marnef F, Poulle M-L, Dumètre A, Thulliez P, Dardé M-L, Villena I. 2011. Development of a sensitive method for Toxoplasma gondii oocyst extraction in soil. Veterinary Parasitology, 183, 59-67.

33. Lélu M, Villena I, Darde M-L, Aubert D, Geers R, Dupuis E, Marnef F, Poulle M-L, Gotteland C, Dumetre A, Gilot-Fromont E. 2012. Quantitative estimation of the viability of Toxoplasma gondii oocysts in soil. Applied and Environmental Microbiology, 78, 5127-5132.

34. Liu Q, Wei F, Gao S, Jiang L, Lian H, Yuan B, Yuan Z, Xia Z, Liu B, Xu X, Zhu X-Q. 2009. Toxoplasma gondii infection in pregnant women in China. Transactions of the Royal Society of Tropical Medicine and Hygiene, 103, 162-166.

35. Mizgajska-Wiktor H, Jarosz W, Fogt-Wyrwas R, Drzewiecka A. 2017. Distribution and dynamics of soil contamination with Toxocara canis and Toxocara cati eggs in Poland and prevention measures proposed after 20 years of study. Veterinary Parasitology, 234, 1-9.

36. Nijsse R, Mughini-Gras L, Wagenaar JA, Franssen F, Ploeger HW. 2015. Environmental contamination with Toxocara eggs: a quantitative approach to estimate the relative contributions of dogs, cats and foxes, and to assess the efficacy of advised interventions in dogs. Parasites \& Vectors, 8, 397.

37. Opel KL, Chung D, McCord BR. 2010. A study of PCR inhibition mechanisms using real time PCR. Journal of the Forensic Science Society, 55, 25-33.

38. Otero-Abad B, Rüegg S, Hegglin D, Deplazes P, Torgerson PR. 2017. Mathematical modelling of Echinococcus multilocularis abundance in foxes in Zurich, Switzerland. Parasites \& Vectors, $10,21$.

39. Overgaauw PAM, van Knapen F. 2013. Veterinary and public health aspects of Toxocara spp. Veterinary Parasitology, 193, 398-403.

40. Piarroux M, Piarroux R, Knapp J, Bardonnet K, Dumortier J, Watelet J, Gerard A, Beytout J, Abergel A, Bresson-Hadni S, Gaudart J, for the FrancEchino Surveillance Network. 2013. Populations at risk for alveolar echinococcosis, France. Emerging Infectious Diseases, 19, 721-728.
41. Piarroux M, Gaudart J, Bresson-Hadni S, Bardonnet K, Faucher B, Grenouillet F, Knapp J, Dumortier J, Watelet J, Gerard A, et al. 2015. Landscape and climatic characteristics associated with human alveolar echinococcosis in France, 1982 to 2007. Euro Surveillance, 20, 18, pii: 21118.

42. Poulle M-L, Forin-Wiart M-A, Josse-Dupuis É, Villena I, Aubert D. 2016. Detection of Toxoplasma gondii DNA by qPCR in the feces of a cat that recently ingested infected prey does not necessarily imply oocyst shedding. Parasite, 23, 29.

43. Raoul F, Hegglin D, Giraudoux P. 2015. Trophic ecology, behaviour and host population dynamics in Echinococcus multilocularis transmission. Veterinary Parasitology, 213, 162-171.

44. Reischl U, Bretagne S, Krüger D, Ernault P, Costa J-M. 2003. Comparison of two DNA targets for the diagnosis of toxoplasmosis by real-time PCR using fluorescence resonance energy transfer hybridization probes. BMC Infectious Diseases, 3, 7.

45. Robert-Gangneux F, Aubert D, Villena I, Villena I. 2015. Toxoplasmosis: a widespread zoonosis diversely affecting humans and animals, in Zoonoses - Infections Affecting Humans and Animals: Focus on Public Health Aspects, Sing A, Editor. Springer: Dordrecht, The Netherlands. p. 355-376.

46. Robertson LJ, van der Giessen JW, Batz MB, Kojima M, Cahill S. 2013. Have foodborne parasites finally become a global concern? Trends in Parasitology, 29, 101-103.

47. Shimalov V, Shimalov V. 2002. Helminth fauna of the red fox (Vulpes vulpes Linnaeus, 1758) in southern Belarus. Parasitology Research, 89, 77-78.

48. Slifko TR, Smith HV, Rose JB. 2000. Emerging parasite zoonoses associated with water and food. International Journal for Parasitology, 30, 1379-1393.

49. Sommerfelt IE, Cardillo N, López C, Ribicich M, Gallo C, Franco A. 2006. Prevalence of Toxocara cati and other parasites in cats' faeces collected from the open spaces of public institutions: Buenos Aires, Argentina. Veterinary Parasitology, 140, 296-301.

50. Szostakowska B, Lass A, Kostyra K, Pietkiewicz H, Myjak P. 2014. First finding of Echinococcus multilocularis DNA in soil: preliminary survey in Varmia-Masuria Province, northeast Poland. Veterinary Parasitology, 203, 73-79.

51. Torgerson PR, Schweiger A, Deplazes P, Pohar M, Reichen J, Ammann RW, Tarr PE, Halkik N, Müllhaupt B. 2008. Alveolar echinococcosis: from a deadly disease to a well-controlled infection. Relative survival and economic analysis in Switzerland over the last 35 years. Journal of Hepatology, 49, 72-77.

52. Umhang G, Comte S, Raton V, Hormaz V, Boucher J-M, Favier S, Combes B, Boué F. 2014. Echinococcus multilocularis infections in dogs from urban and peri-urban areas in France. Parasitology Research, 113, 2219-2222.

53. Umhang G, Forin-Wiart M-A, Hormaz V, Caillot C, Boucher J-M, Poulle M-L, Franck B. 2015. Echinococcus multilocularis detection in the intestines and feces of freeranging domestic cats (Felis s. catus) and European wildcats (Felis s. silvestris) from northeastern France. Veterinary Parasitology, 214, 75-79.

54. Veit P, Bilger B, Schad V, Schäfer J, Frank W, Lucius R. 1995. Influence of environmental factors on the infectivity of Echinococcus multilocularis eggs. Parasitology, 110, 79-86.

55. Villeneuve A, Polley L, Jenkins E, Schurer J, Gilleard J, Kutz S, Conboy G, Benoit D, Seewald W, Gagné F. 2015. Parasite prevalence in fecal samples from shelter dogs and cats across the Canadian provinces. Parasites \& Vectors, 8, 281. 
Cite this article as: Poulle M-L, Bastien M, Richard Y, Josse-Dupuis É, Aubert D, Villena I \& Knapp J: Detection of Echinococcus multilocularis and other foodborne parasites in fox, cat and dog faeces collected in kitchen gardens in a highly endemic area for alveolar echinococcosis. Parasite, 2017, 24, 29.

\section{O PARASTE}

An international open-access, peer-reviewed, online journal publishing high quality papers on all aspects of human and animal parasitology

Reviews, articles and short notes may be submitted. Fields include, but are not limited to: general, medical and veterinary parasitology; morphology, including ultrastructure; parasite systematics, including entomology, acarology, helminthology and protistology, and molecular analyses; molecular biology and biochemistry; immunology of parasitic diseases; host-parasite relationships; ecology and life history of parasites; epidemiology; therapeutics; new diagnostic tools.

All papers in Parasite are published in English. Manuscripts should have a broad interest and must not have been published or submitted elsewhere. No limit is imposed on the length of manuscripts.

Parasite (open-access) continues Parasite (print and online editions, 1994-2012) and Annales de Parasitologie Humaine et Comparée (1923-1993) and is the official journal of the Société Française de Parasitologie. 